Mid-American Review of Sociology

Swift, W.J. and S. Stern. 1982. "The Psychodynamic Diversity of Anorexia Nervosa." International Journal of Eating Disorders 2:17-35.

Turner, Victor. 1967. The Forest of Symbols. Ithaca, NY: Cornell University Press.

1969. The Ritual Process: Structure and Anti-Structure. Ithaca, NY: Cornell University Press.

Van Gennep, Arnold. 1909. The Rites of Passage, trans. Monika B. Vizedom and Gabrielle L. Caffee. Chicago: University of Chicago Press, 1960.

Wilson, C.P. 1983. "The Family Psychological Profile and Its Therapeutic Implications." In The Fear of Being Fat: The Treatment of Anorexic Nervosa and Bulimia, edited by C. P. Wilson, et al. New York: Jason Aronson.

Winnicott, Donald W. 1988. Human Nature. London: Free Association Books.

\section{RESEARCH EXAMINING IMPACTS OF ATTEMPTS TO CHANGE PATTERNS OF ALCOHOL CONSUMPTION AND RELATED BEHAVIORS}

Richard A. Dodder

Oklahoma State University

Stella P. Hughes

South Dakota School of Mines and Technology

Mid-American Review of Sociology, 1990, Vol. XIV, No. 1-2:145-150.

An issue of considerable concern in American society has been that of problems resulting from alcohol consumption. Our research during the past few years has focused on attempting to understand this phenomenon and how it relates to other behavior patterns. Specifically, we have been involved in research evaluating consequences of laws and programs designed to impact drinking behaviors. In addition to these practical policy concerns, we have also focused on testing implications of neutralization and deterrence theories as sociological explanations for the domain of alcohol use and abuse. Methodologically we have focused on self-administered questionnaire formats in longitudinal designs in order to be able to examine subjects and variables over time. We have also been interested in examining response differences among student-nonstudent populations, variations in drinking patterns among racial and ethnic groups, and response differences that might occur as a result of changes in item wording on questionnaires.

During the early 1970 s a trend developed in the U.S. to lower the minimum drinking age. In subsequent years, increases in accident rates among young drivers were reported, and some states then began to raise the minimum drinking age. Research seeking to understand the relationship between the drinking age and alcohol related behaviors, including accident rates, however, has produced inconsistent results (cf. Hanson, Engs, and Katter 1984; Rooney and Schwartz 1977; Williams, Rich, Zador, and Robertson 1975; Naor and Nashold, 1975). In September of 1983, the Oklahoma legislature joined those states changing the drinking age by passing a bill to raise the minimum drinking age for 3.2 beer from 18 to 21 (the minimum age for wine and distilled spirits was already 21).

A three-year grant was obtained from The National Institute of Alcohol Abuse and Alcoholism (NIAAA) to examine alcohol consumption and related behavior patterns among Oklahoma State University students, both before and after implementation of the new law. The research focused on changes in drinking patterns that occurred both over time and in relation to baseline data collected in 1981 .

Questionnaires were completed by students in randomly selected Introductory Sociology classes at Oklahoma State University just prior to implementation of the legislation (September 1983); and the same methodology was repeated each semester through the spring of 1987. A total 
of ten samples were obtained containing information from 6,034 students. These ten samples were examined and found to be demographically similar, thus allowing us to make more direct comparisons across samples without having the complication of changes in sample composition over time.

Analysis of the short-term effects of raising the minimum drinking age (after one year) found an increase in drinking just prior to the law change followed by a decrease in the sampling period just subsequent to implementation (Hughes and Dodder 1986). There were fewer apparent changes among males but reports of more reduced drinking among females. In addition, students indicated drinking less often in bars and other public places, but more often at home or in college residences. They also reported drinking less beer but more wine and distilled spirits. Responses indicated that students were obtaining beer (as well as other alcoholic beverages) primarily from friends who were of legal age and from store clerks who did not ask for proof of age. Informal interviews and other qualitative research suggested, in addition, that after the law change a frequent response was to drive to a convenience store, have a legal-age friend purchase a 12-pack of beer, and drive around town drinking. Such findings offer little support for raising the minimum drinking age as a way to reduce drinking, and thus drinking and driving.

Because there has not been consensus on measurement of quantity or frequency of alcohol consumption, three different formats for obtaining this information were presented during the early part of the research. Conclusions from analyzing the effects of these different formats were that even small differences in question wording and response categories can have a significant impact on the results obtained (Hughes and Dodder 1988).

Analyses of many of the related variables and of the longterm effects have not been completed; however, initial findings regarding the longterm effects indicate that few significant changes in drinking patterns are apparent particularly with respect to quantity and frequency of consumption (Hughes 1988). The initial changes in drinking patterns were not maintained over time but instead the quantity and frequency measure converged-near the level of the baseline data.

In addition to these practical concerns, one of our enduring interests has been neutralization theory and its ability to explain a variety of forms of deviance--in this case, patterns of alcohol consumption and related behaviors. Sykes and Matza (1957) introduced neutralization theory to explain delinquen behavior over thirty years ago. Contrary to many explanations, this theory maintains that delinquent youth do not reject the prevailing moral principles which they violate but accept them while finding temporary justifications for behaviors which run counter to these principles. Thus, greater neutralization (accepting temporary justifications for behavior which run counter to accepted moral principles) is expected to relate to greater drinking. In addition, since neutralizations provide acceptable reasons to oneself for engaging in an act, consequences of that act which are psychological (e.g., thinking one has a drinking problem) would presumably decrease. But since greater neutralization is expected to result in greater drinking, non-psychological problems resulting from greater drinking (driving accidents) are expected to increase.

Although neutralization theory has been used successfully in a variety of research on deviance (e.g., crime and delinquency, taxi-dancing, religious dissonance, drug usage, abortion, abuse, rental housing, poker playing), only one known project (Norris and Dodder 1979) has looked at alcohol use from a neutralization perspective.

Our preliminary paper examining alcohol consumption and related behaviors (Dodder and Hughes 1987) found that greater acceptance of neutralizations related consistently to greater quantity and frequency of drinking as well as to more drinking-related problems. In addition, the neutralizations that subjects accepted followed the classical five types originally identified by Sykes and Matza (1957)--the denial of responsibility ("It's O.K. to drink at a party when everyone else is drinking"), the denial of injury ("Drinking is O.K. as long as you don't get drunk and harm others"), the denial of a victim ("It's really no one's business how much people drink as long as they don't annoy others"), condemnation of condemners ("Drinking is no worse than many other things people do today"), and appeal to higher loyalties ("It's O.K. to drink in order to stay in good with one's friends"). When the subject's acceptance of both the moral principle and the neutralizations to it were considered, however, results were considerably less consistent and less supportive of neutralization theory.

From this first project, we changed our focus somewhat and completed a much broader analysis, the results of which were presented at the Southwestern Social Sciences Association meeting in the spring of 1989. From this analysis we concluded that neutralization theory anticipates data well when the domain of application is restricted. That is, those who accepted the principle that drinking is O.K. also tended to accept temporary justifications for drinking. In addition, these subjects tended to drink more as they accepted these justifications. But there was no consistent pattern of neutralizing and experiencing various types of alcohol related problems. Abstainers overwhelmingly accepted the moral principle and the neutralizations of this principle as well. The great majority of subjects $(82.6 \%)$, however, rejected the moral principle that drinking is O.K., severely curtailing the utility of neutralization theory.

While completing the minimum drinking age research, we were involved in a related project with the local police department. Police officials had concluded that arresting drunk drivers was not impacting the problem appreciably and were interested in addressing the problem by designing a community-wide education program. Although research of community wide education programs is scarce, there has been a number of efforts to examine programs developed for specially targeted groups. Some projects, for example, have attempted to educate high risk drivers but with limited success (Maistro, Sobell, Zelhart, Connors, and Cooper 1979). Other projects have created programs for those arrested for alcohol offenses. Some of these have reported 
successful results (e.g. Ellingstad and Springer 1976) while others have been less optimistic (e.g., Reis and Davis 1980).

The local police department project, for which we served as consultants and designed the evaluation strategy, targeted the entire community. It featured educational efforts aimed at both adults and youth, and was designed to increase knowledge of alcohol and to encourage more responsible drinking behavior. Prior to inception of this project in November of 1985, we gathered baseline data at the local Tag Agency. In Oklahoma everyone must appear in person at the Tag Agency in their county of residence to obtain a driver's license or to renew their license every four years. Self-administered questionnaires were given in September and October of 1985 to every person applying for or renewing their drivers's license. These questionnaires were completed while subjects waited for their pictures to be developed for their licenses. Data were then gathered every September-October for the two years of the duration of the project and for one year following its completion generating a sample of 1,923 .

In order to continue our research in refining methodology we also collected samples, using the same instrument and time frame, of college students in randomly selected sections of Introductory Sociology classes $(\mathrm{N}=1,594)$. This will enable us to compare samples of student and adult drivers and of students in two different settings.

In evaluating data from the police department project, we will not only be able to add to the available knowledge concerning the impact of community wide educational programs oriented toward encouraging more responsible alcohol behavior, but we also hope to shed some light on the impacts of various programs within the total project and the policy implications of such programs.

Our theoretical interest from the early talking stages in this project was deterrence theory, particularly individual perceptions of sanctions: legal, moral, and social. Deterrence theory follows a rational-choice model, suggesting that if for a given person, the expected utility of an illegal act is greater than the expected utility of alternatives, the person will engage in the illegal act (Piliavin, Gartner, Thornton, and Matsueda 1986). While the literature is rich in contributions addressing deterrence: the research has typically been with students only, has used either cross-sectional or panel designs, and has tended to measure perceptions of deterrence with a composite scale rather than with behavior-specific indicators. In this project, we wanted to identify both inhibitors and motivators of alcohol related behaviors of driving adults and students in a longitudinal design with questions specific to subjects perceptions of alcohol and the law. Consequently, this research should help us address some of the continuing problems in deterrence research as well as to provide some possible explanations of whatever changes may be found.

Since we have just completed data collection, analysis has only begun. Earlier analysis on the baseline data, however, suggested that those subjects who believed they would suffer greater penalties for drinking and for drunk driving as well as those who were more likely to believe they would be caught if they engaged in drunk driving were also those who drank more and who engaged in drinking and driving more often. In addition, those who had been arrested for driving while intoxicated also believed the penalties to be more arrested these preliminary findings harsh than diewed as supportive of deterrence theory; however, more analysis and thought is needed before firm conclusions can be drawn--partially because the actual penalties for alcohol related offenses and the likelihood of being the actual penaltes for are not high. That is, people may accurately know how harsh the penalties are and decide to engage in the behavior because the penalties are not harsh enough to deter them. As one young woman put it, "If you don't drink, there's nothing to do in this town. And even if you get caught, what difference does it make. You only have to do 20 hours of community service; and it doesn't even go on your record."

\section{REFERENCES}

Dodder, R. A. and S. P. Hughes. 1987. "Collegiate Drinking Behavior: A Test of Neutralization Theory." Joumal of Alcohol and Drug Education 33:35-40.

Ellingstad, V. S. and T. J. Springer. 1976. Program Level Evaluation of ASAP Rehabilitation Countermeasures Effectiveness: Final Report. Prepared for the U.S. National Highway Traffic Safety Administration (Rep. No. for the U.S. National Highway Traffic Safety Administration (Rep. Not Information Service.

Hansen, D. J., R. C. Engs and H. Katter. 1984 "College Students' Attitudes Toward Drinking--1983: Exploring Socialization Theory." College Student Journal 18:4425-29.

Hughes, S. P. 1988. "Legal-Age Barriers Have Little Effect." U.S. Joumal of Drug and Alcohol Dependence March:8.

Hughes, S. P. and R. A. Dodder. 1988. "Alcohol Consumption Indices." Journal of Studies on Alcohol 49:100-103.

1986. "Raising the Legal Minimum Drinking Age: Short-Term Effects with College Students." Journal of Drug Issues 17:609-20.

Maistro S. A L C. Sobell, P. F. Zelhart, G. J. Connors, and T. Cooper. 1979. "Driving Records of Persons Convicted of Driving Under the Influence of Alcohol." Journal of Studies on Alcohol 40:70-7.

Naor, E M and R. D. Nashold. 1975 "Teenage Driver Fatalities Following Reduction in the Legal Drinking Age." Joumal of Safety Research 7:74-9.

Non orris, T. D. and R. A. Dodder. 1979. "A Behavioral Continuum Synthesizing Neutralization Theory

Piliavin, I. R. Gartner, C. Thornton, and R. L. Matsueda. 1986. "Crime, iliavin, I., R. Gartner, C. Thornton, and R. L. Merican Review of Sociology 51:101-19. 


\section{Mid-American Review of Sociology}

Rooney, J. F. and S. M. Schwartz. 1977. "The Effect of Minimum Drinking Age Laws upon Adolescent Alcohol Use and Problems." Contemporary Drug Problems 6.569-83.

Reis, R. E. and L. A. Davis. 1980. First Interim Analysis of First Offender Treatment Effectiveness: Comprehensive Driving Under the Influence of Alcohol Offender Treatment Demonstration Project. Prepared for the U.S. Highway Safety Administration (Rep. No. DOT-HS-6-01414). Springfield, VA: U.S. National Technical Information Service.

Sykes, G. M., and D. Matza. 1957. "Techniques of Neutralization: A Theory of Delinquency." American Sociological Review 22:664-670.

Williams, A. F., R. F. Rich, P. L. Zador, and L. S. Robertson. 1975 "The Legal Minimum Drinking Age and Fatal Motor Vehicle Crashes." The Journal of Legal Studies 4:219-39.

\section{"IT'S JUST AS EASY TO MARRY A RICH MAN AS A POOR ONE" STUDENTS' ACCOUNTS OF PARENTAL MESSAGES ABOUT \\ MARITAL PARTNERS}

\author{
Jane E. Prather \\ California State University, Northridge
}

Mid-American Review of Sociology, 1990, Vol. XIV, No. 1-2:151-162

Finding appropriate marital partners for their children is a universal concern for parents. In contrast to traditional societies where parents actively seek and select marital partners for their offspring, American society presents the illusion that children have freedom and choice in selecting marital partners. No society, however, really allows people to actually choose their marriage partners on a completely individual basis (Eshleman 1988, p. 254). American parents have not left these important decisions solely to chance. Even though single Americans may assume they are making independent choices, years of socialization lead them to prefer certain categories of persons for marriage and they can only exercise limited freedom of choice (Eshleman 1988 , p. 255). Especially for first and early marriage, couples face considerable social pressure from both parents and peers if they choose to ignore this socialization.

Another American folklore is that couples should only marry if romantically in love (Lee 1982, p. 173). William Goode (1959), however, argues no society allows love to reign without boundaries. Instead, he suggests that societies structure the opportunities and settings where ideal love can occur with higher social classes attempting to exercise more effective control over love than lower classes.

In the United States homogamy in race, religion, occupational class, education, and age range occurs at levels higher than expected by chance (Eshleman 1988; Rockwell 1976; Adams 1979). Even in second marriages where parental influence is usually minimal, homogamy in the above categories is still practiced (Peters 1980).

Over thirty years ago sociologist Marvin Sussman described American parents as threatening, cajoling, wheedling, bribing and in other ways attempting to deter their children from what they considered to be "poor" marriages (1953, p. 80). He noted parents sought to control love by influencing the informal social contacts of their children, through such means as moving into appropriate neighborhoods, sending students to approved schools, and hosting weekend and holiday parties so that children only had opportunities to meet eligible partners.

In Crestwood Heights, a community study of a Canadian suburb, parents asserted that their children's marriages should be based , "...on love, sympathy, compatibility, without regard to race, creed or color or above all--the ugly word!--money." (Seeley, Sim and Loosley 1956, p. 96). Yet, the authors concluded: "the marriages that do occur are not notably different from those 